\title{
Impaired Healing of a Cutaneous Wound in an Inducible Nitric Oxide Synthase-Knockout Mouse
}

\author{
Takashi Kitano, ${ }^{1}$ Hiroshi Yamada, ${ }^{1}$ Maki Kida, ${ }^{2}$ Yuka Okada, ${ }^{3}$ \\ Shizuya Saika, ${ }^{3}$ and Munehito Yoshida ${ }^{1}$ \\ ${ }^{1}$ Department of Orthopedic Surgery, Wakayama Medical University School of Medicine, 811-1 Kimiidera, Wakayama 641-0012, Japan \\ ${ }^{2}$ Department of Ophthalmology, Wakayama Medical University School of Medicine, 811-1 Kimiidera, Wakayama 641-0012, Japan \\ ${ }^{3}$ Department of Critical Care Medicine, Wakayama Medical University School of Medicine, 811-1 Kimiidera, \\ Wakayama 641-0012, Japan
}

Correspondence should be addressed to Takashi Kitano; pmmmy836@ybb.ne.jp

Received 6 February 2017; Accepted 28 February 2017; Published 13 April 2017

Academic Editor: Markus Stucker

Copyright (C) 2017 Takashi Kitano et al. This is an open access article distributed under the Creative Commons Attribution License, which permits unrestricted use, distribution, and reproduction in any medium, provided the original work is properly cited.

\begin{abstract}
Background. We investigated the effects of loss of inducible nitric oxide synthase (iNOS) on the healing process of cutaneous excisional injury by using iNOS-null (KO) mice. Population of granulation tissue-related cell types, that is, myofibroblasts and macrophages, growth factor expression, and reepithelialization were evaluated. Methods. KO and wild type (WT) mice of C57BL/6 background were used. Under general anesthesia two round full-thickness excision wounds of $5.0 \mathrm{~mm}$ in diameter were produced in dorsal skin. After specific intervals of healing, macroscopic observation, histology, immunohistochemistry, and real-time reverse transcription-polymerase chain reaction (RT-PCR) were employed to evaluate the healing process. Results. The loss of iNOS retards granulation tissue formation and reepithelialization in excision wound model in mice. Detailed analyses showed that myofibroblast appearance, macrophage infiltration, and mRNA expression of transforming growth factor $b$ and of collagen $1 \alpha 2$ were all suppressed by lacking iNOS. Conclusions. iNOS is required in the process of cutaneous wound healing. Lacking iNOS retards macrophage invasion and its expression of fibrogenic components that might further impair fibrogenic behaviors of fibroblasts.
\end{abstract}

\section{Introduction}

Rapid and well-organized wound healing in skin is essential to health maintenance by reducing risks of bacterial contamination, inhibition of water loss, suppression of scar formation that might perturb organ function, and so forth. Therefore, the mechanism of skin wound healing is to be wellunderstood in order to develop strategies to overcome impaired wound healing in conditions such as pressure ulcer and diabetic wounds.

The process of cutaneous wound healing overall consists of stages of so-called hemostasis, proliferation, and maturation [1-3]. The stage of "hemostasis" is the first stage preventing excessive blood loss and the trigger events that lead to local inflammation by neutrophils and then macrophages. The inflammation is followed by the performance of local tissue cells, that is, keratinocyte and fibroblast. The former cells first migrate into the injured area for the primary coverage and start to proliferate to recover the stratification. The latter transforms to the myofibroblast that is capable of producing extracellular matrix (ECM) and of tissue contraction. Both cell migration of keratinocytes and fibroblast-myofibroblast conversion largely depend on the activity of a potent growth factor, transforming growth factor $\beta$ (TGF $\beta$ ), although a set of growth factors are believed to orchestrate the whole process of tissue repair [3].

Nitric oxide (NO) is implicated in cellular and molecular events of aspects of wound healing, that is, vasodilation, angiogenesis, inflammation, tissue fibrosis, or immune responses [4-6]. These reports overall suggest NO synthesis is essential to the uncomplicated cutaneous wound healing. However, controversial results were reported in types of wound models $[7,8]$. NO production is mediated by inducible nitric oxide synthase (iNOS) that is regulated independently of intracellular calcium elevations $[9,10]$. Initial 
injury is followed by infiltration of inflammatory cells, that is, neutrophils and macrophages, fibroblast repopulation and its transformation to myofibroblast, and new vessel formation as well as keratinocyte migration and proliferation. The major source of TGF $\beta$ in a tissue under repairing process is considered to be macrophage. Recruitment of macrophage to an injured tissue is stimulated by NO [11-13]. Moreover, NO reportedly modulates expression of TGF $\beta$ [7]. It is therefore hypothesized that NO might affect the healing process of cutaneous injury.

To address this question, in the present study we took an advantage of the availability of a mouse line of C57BL/6 background that lacks iNOS gene in our laboratory. To clear a disadvantage of the qualitative assessment of the wound healing process in the skin, we investigated statistical analysis of the incidence of closure of circular excision injury in the dorsal skin of mice during healing intervals, employing macroscopic observation, histology, immunohistochemistry, and detection of mRNAs using real-time reverse transcriptionpolymerase chain reaction (RT-PCR). Our statistical analysis showed that primary healing of excision cutaneous injury is impaired by the loss of iNOS in association with suppression of macrophage population and fibrogenic gene expression.

\section{Materials and Methods}

Experiments were approved by the DNA Recombination Experiment Committee and the Animal Care and Use Committee of Wakayama Medical University.

2.1. Excision Wound Model in Mice. iNOS-knockout (KO) and wild type (WT) mice, both of C57BL/6 background and 8 to 10 weeks old, were used in the experiments. Under general anesthesia with intraperitoneal administration by pentobarbital sodium $(70 \mathrm{mg} / \mathrm{kg}$ of body weight) $[14,15]$, the dorsal hairs were shaved and the exposed skin was wiped with $70 \%$ ethanol. Two round full-thickness excision wounds of 5.0 $\mathrm{mm}$ in diameter were produced in dorsal skin by picking up a fold skin at the midline and using a sterile disposable biopsy trephine (Kai Industries, Gifu, Japan) and a surgical blade as previously reported by us [16]. The wounds arranged lengthways were made at the same time. Ofloxacin ointment $(0.3 \%)$ was topically applied to the wounds to reduce the risk of bacterial contamination every day during the first 7 postwounding days. The mouse with an apparent sign of infection was excluded.

2.2. Macroscopic Wound Observation. Six KO and 6 WT mice were used for the analysis in macroscopic findings. The wound was photographed with SZ-PT (Olympus, Tokyo, Japan) at intervals of healing $(0,1,3,6,8,11$, and 14 days). The size of remaining skin defect (as the percentage of the initial wound area) was evaluated by using Photoshop software (Version 8.0, Adobe Systems, Tokyo, Japan) and statistically analyzed.

2.3. Histology of Healing Tissue. Thirty-two KO and $32 \mathrm{WT}$ mice were killed at specific intervals of healing $(3,6,8,11$, and
14 days) with an overdose of diethyl ether and processed for histology. Two round excision wounds including the epithelial margins were excised $5.0 \mathrm{~mm}$ in diameter with a sterile disposable biopsy trephine and a surgical blade. The tissue excised wound was fixed with $4.0 \%$ paraformaldehyde in $0.1 \mathrm{M}$ phosphate buffer ( $\mathrm{pH} 7.4$ ) for 48 hours and embedded in paraffin and processed for histology. Paraffin sections $5 \mu \mathrm{m}$ thick were cut and stained with hematoxylin and eosin (HE). We measured the thickness of granulation tissue at the two following points of the healing wound; one point was the center zone with the minimum thickness of the granulation tissue; another was the margin zone with the maximum thickness of the granulation tissue [17]. These data of the thickness of granulation tissue were statistically analyzed. MassonGoldner trichrome stain was also performed for the visualization of collagenous connective tissue in the regenerated healing tissue.

2.4. Reepithelialization in Excisional Skin Wound Healing. We further analyzed the reepithelialization in excision skin wound healing with $\mathrm{KO}$ and WT mice at specific intervals of healing at the histological level (3, 6, 8, 11, and 14 days). For this purpose we used tissue stained with Masson-Goldner trichrome. The percentage of the reepithelialization to the original wound area was calculated as follows: reepithelization (\%) $=[$ distance covered by epithelium $] \times 100 /[$ distance between original wound edge] [18-21].

2.5. Immunohistochemistry. Immunohistochemical analysis was performed for the evaluation of the cellular components in the regenerated tissue. Deparaffinized sections were processed for indirect immunohistochemistry as previously reported $[22,23]$. The following antibodies were used [22, 23]; the presence of monocytes/macrophages was examined by using rat monoclonal F4/80 anti-macrophage antigen antibody (Clone A3-1, 1: 400; BMA Biomedicals, August, Switzerland). The mouse monoclonal anti- $\alpha$-smooth muscle actin $(\alpha$ SMA) antibody (Clone 1A4, 1:100; Neomarkers, Fremont, CA) was used to detect myofibroblast. Two visual fields $(\times 400)$ were chosen from each edge of the wound bed; the other three were chosen from the middle of the wound bed at 6 and 8 days after the injury. The numbers of F4/80-positive macrophages and myofibroblasts as detected by $\alpha \mathrm{SMA}$ expression within a wound bed were enumerated on these five visual fields $[24,25]$.

2.6. Detection of $m R N A s$ Using Real-Time Reverse Transcription-Polymerase Chain Reaction (RT-PCR). Two round wounds of $5.0 \mathrm{~mm}$ in diameter were produced using trephine and a blade in dorsal skin of each of $24 \mathrm{KO}$ and $24 \mathrm{WT}$ mice. For extraction of RNA, a round newly healed tissue was excised using trephine and a blade with the same size as the original wound at days 3, 6, and 8 and stored at deep freezer $\left(-80^{\circ} \mathrm{C}\right)$. Total RNA was obtained using Sigma GenEluted ${ }^{\mathrm{TM}}$ Mammalian Total RNA Miniprep Kit (Sigma-Aldrich Co., St. Louis, MO) as previously reported [26-28]. Expression of mRNAs of $\alpha$ SMA, F4/80, transforming growth factor $\beta 1$ (TGF $\beta 1$ ), and collagen $1 \alpha 2$ in newly regenerated tissue was evaluated by RT-PCR. The TaqMan one-step RT-PCR master 


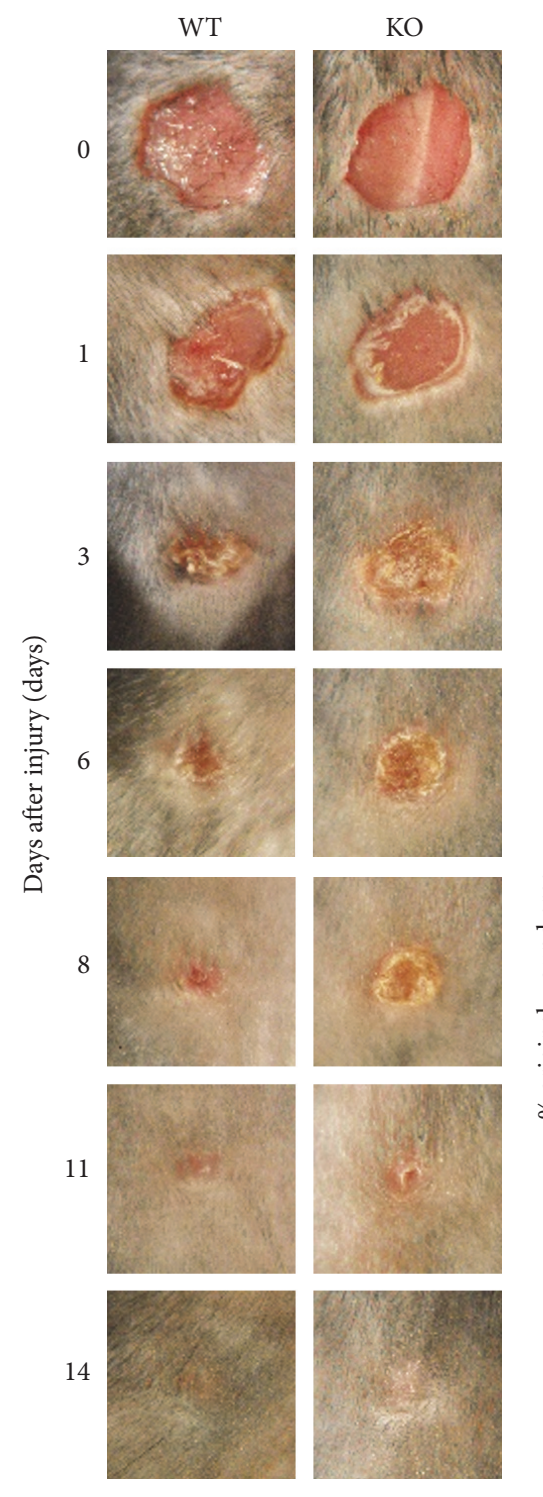

(a)

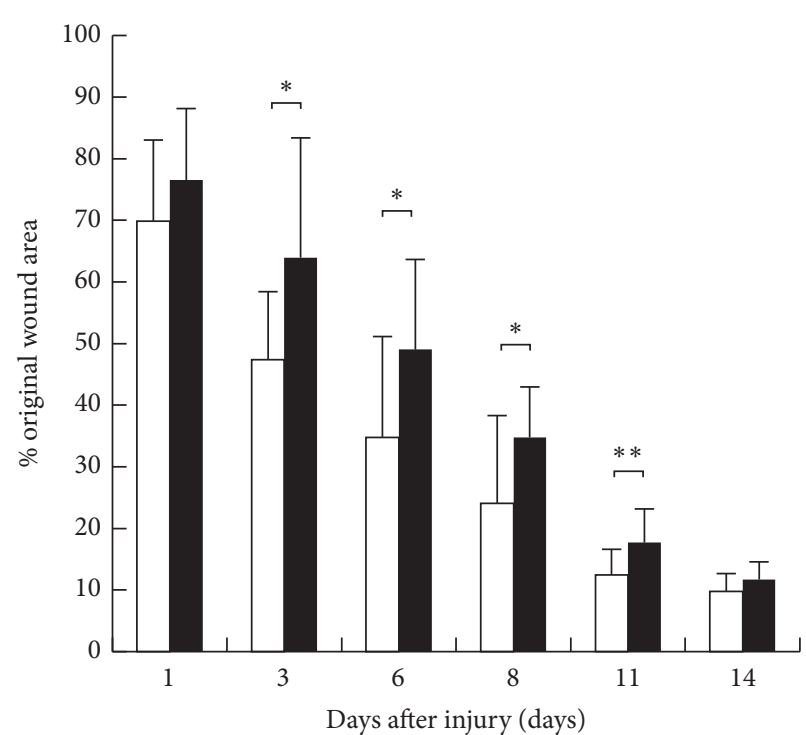

(b)

FIGURE 1: (a) Macroscopic wound findings of cutaneous excision wound healing in dorsal skin of inducible nitric oxide synthase (iNOS-) knockout (KO) mice and wild type (WT) mice. (b) Unhealed wound area changed in percentage to the original wound area in each time point. At the time points of 3,6,8, and 11, the remaining skin defect was larger in KO mice than WT mice with a statistically significant difference. Open bars: WT, filled bars: $\mathrm{KO}\left(n=7\right.$ animals in each group). Mean \pm standard deviation. ${ }^{*} p<0.05 ;{ }^{* *} p<0.01$.

mix reagents kit and the Applied Biosystems Prism 7700 (PE Applied Biosysems, Foster City, CA) were used as described previously [26-28]. Primers and oligonucleotide probes were designed according to the cDNA sequences in the GenBank database using the Primers Express software (PE Applied Biosystems).

2.7. Statistical Analysis. The means and standard deviations were calculated for all parameters determined in this study. Statistically significant difference was evaluated by using unpaired Student's $t$-test. $p<0.05$ was accepted as statistically significant.

\section{Results}

3.1. Macroscopic Findings of Wound Healing. To evaluate the healing process of the dorsal excision wounds of $\mathrm{KO}$ and WT mice, we examined the size of remaining skin defect areas (as percentage of the original wound size) at each healing interval (Figure 1(a)). One day after injury, skin defects of KO mice were of similar morphology compared with WT mice. At the time points of 3,6,8, and 11, the remaining skin defect was larger in KO mice than WT mice with a statistically significant difference (Figure 1(b)). In WT mice, wound areas were reduced to $50 \%$ of the original wound areas at day 3 after injury. In contrast, wound areas in $\mathrm{KO}$ mice still remained 
at $50 \%$ even at day 6 after injury. At day 14 after the injury, cutaneous defects had no such difference. These observations demonstrated that healing of a full-thickness cutaneous wound was delayed in the absence of iNOS.

\subsection{Histological Analysis of Granulation Tissue Formation.} The defect of dermis was gradually closed by newly formed granulation tissue that was covered with epidermis during skin healing process. For this purpose we employed histological observation by $\mathrm{HE}$ staining (Figure 2(a)). We measured the thickness of granulation tissue at the center and margin zone in the healing wound as previously reported by us. The results showed that the thickness of the granulation tissue at the center zone was thinner in KO mice than in WT mice at days 6 and 8 with a statistically significant difference (Figure 2(b)). At the margin zone, the thickness of the granulation tissue was significantly thinner in $\mathrm{KO}$ mice than in WT mice at day 6 (Figure 2(c)).

3.3. Evaluation of Reepithelialization. Newly formed granulation tissue in full-thickness cutaneous wound is associated with reepithelialization by keratinocytes. We evaluated the reepithelialization in skin wound healing in $\mathrm{KO}$ and WT tissues stained with Masson-Goldner trichrome at specific intervals of healing (Figures 3(a)-3(d)). At day 1 after injury, regeneration of stratified epithelium could not be observed in both WT and KO mice (data was not shown). At 3 days after injury, there seemed to be no difference of the process of reepithelialization between $\mathrm{KO}$ and WT mice. Reepithelialization was significantly delayed in $\mathrm{KO}$ mice at days 6 and 8 with statistical difference compared with WT mice (Figure 3(e)). The original wound was covered completely with epithelium in day 11 in both WT and KO mice. The results suggested that loss of iNOS retards reepithelialization by keratinocytes in the process of healing of an excision cutaneous injury.

3.4. Immunohistochemical Analysis. The nature of cellular components in the new granulation tissue was evaluated by immunohistochemistry. Although inflammatory cell types infiltrate into the healing tissue, macrophages reportedly play critical roles in the formation of granulation tissue or neovascularization via expression of growth factors. Figure 4 indicates the immunohistochemical detection of F4/80-labeled macrophages at day 6. The infiltration of macrophages in $\mathrm{KO}$ healing tissue was reduced as compared with WT mice at days 6 and 8 after injury with a statistical significance being compared (Figure 4(e)).

Figure 5 shows the immunohistochemical distribution of myofibroblasts as detected by $\alpha$ SMA expression at day 6 . Population of myofibroblasts was suppressed by the loss of iNOS at days 6 and 8 after injury as compared with WT mice with a statistical significance (Figure 5(e)). These results suggested that inhibition of macrophage invasion and myofibroblast appearance could explain the attenuation of granulation tissue formation and resultant epithelial resurface in $\mathrm{KO}$ healing tissue.

3.5. mRNA Expression of Normal Skin of WT and KO Mice. We examined the basal level of expression of $\alpha \mathrm{SMA}, \mathrm{F} 4 / 80$,
TGF $\beta 1$, and collagen $1 \alpha 2$ by performing real-time RT-PCR in cutaneous tissue of $\mathrm{KO}$ and WT mice. Although variation of the data among each animal seemed larger, the data indicated obvious difference between WT and KO mice. Expression of $\alpha$ SMA, F4/80, and TGF $\beta 1$ mRNA was significantly more marked in $\mathrm{KO}$ normal skin tissue compared with WT tissues (Figures 6(a)-6(c)). There was no significant difference of the expression level of collagen $1 \alpha 2$ mRNA between $\mathrm{KO}$ and $\mathrm{WT}$ tissues (Figure 6(d)).

3.6. Gene Expression in Newly Regenerated Tissue of a Healing Wound. We then evaluated the expression pattern of mRNA of F4/80, TGF $\beta 1, \alpha \mathrm{SMA}$, and collagen $1 \alpha 2$ in healing tissues of $\mathrm{KO}$ and WT mice at days 3,6 , and 8 by using real-time RTPCR. F4/80 mRNA expression increased during healing process in both genotypes of mice. Although variation of the data among each animal seemed larger, the data indicated obvious difference between WT and KO mice. Expression of these components was significantly suppressed in $\mathrm{KO}$ tissues as compared with WT tissues at day 6 (Figure 7(a)). Expression of TGF $\beta 1$ mRNA also increased in healing tissue and was significantly less in $\mathrm{KO}$ tissues as compared with WT tissues at days 6 and 8 (Figure 7(b)). Expression of $\alpha$ SMA mRNA was significantly less marked in $\mathrm{KO}$ tissues as compared with WT tissues at day 8 (Figure $7(\mathrm{c})$ ). Collagen $1 \alpha 2 \mathrm{mRNA}$ expression was reduced in $\mathrm{KO}$ tissues as compared with WT tissues at days 3 and 8 with statistically significant difference (Figure $7(\mathrm{~d}))$.

\section{Discussion}

In the present study, we showed that the healing of a circular excision wound in the dorsal skin was significantly impaired by the loss of iNOS in mice. Histology indicated that the formation of granulation tissue and reepithelialization were both attenuated in KO mice as compared with WT mice at each specific time point. Wound NO synthesis inhibition by blocking NOS activity or gene knockout reportedly impairs wound healing, in particular, collagen synthesis [7, 8, 29-31], that coincides with the current study.

Our current immunohistochemical analysis and realtime RT-PCR further confirmed the histology findings; invasion of macrophages and myofibroblast appearance were both suppressed by lacking iNOS. Macrophages reportedly play a critical role in the cutaneous healing by expressing a set of growth factors including TGF $\beta$ [32]. Although various growth factors are involved in the process of tissue repair, $\operatorname{TGF} \beta$ is one of the most important ligands involved in the regulation of cell behavior in physiological or pathological processes of tissue repair [33]. Present study showed that expression of TGF $\beta 1$ mRNA was significantly attenuated in $\mathrm{KO}$ healing tissues as compared with WT tissues at days 6 and 8 . Previous studies suggest that NO is involved in migration and activation of TGF $\beta 1$ of macrophages [34] that coincides with the present findings. Appearance of myofibroblasts and accumulation of provisional extracellular matrix is gradually replaced with a collagenous matrix, presumably as a result of the action of TGF $\beta 1[35,36]$. Real-time RT-PCR also indicated that the mRNA expression of collagen $1 \alpha 2$ was less in 


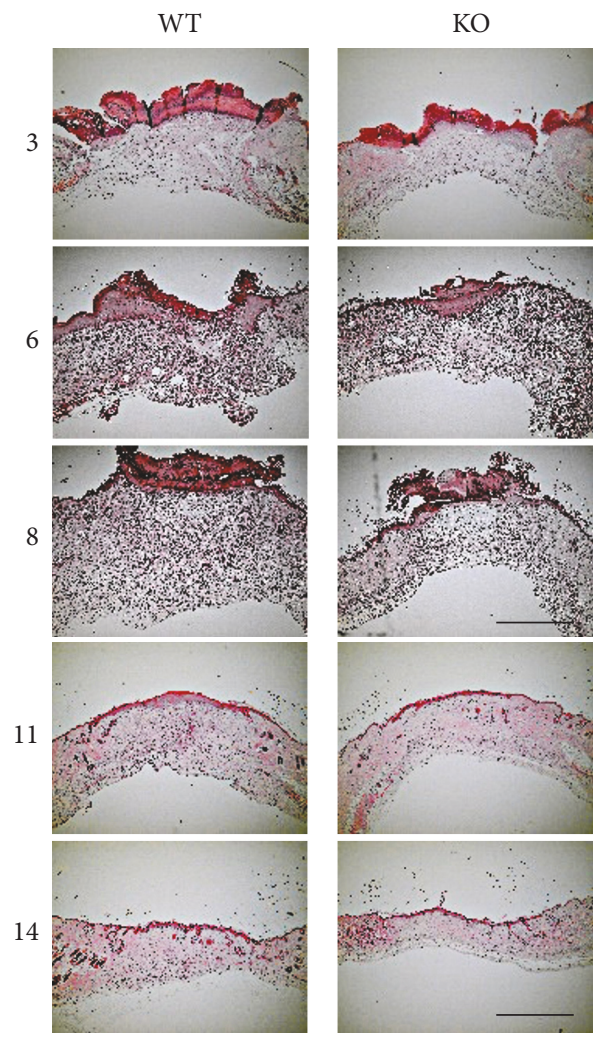

(a)

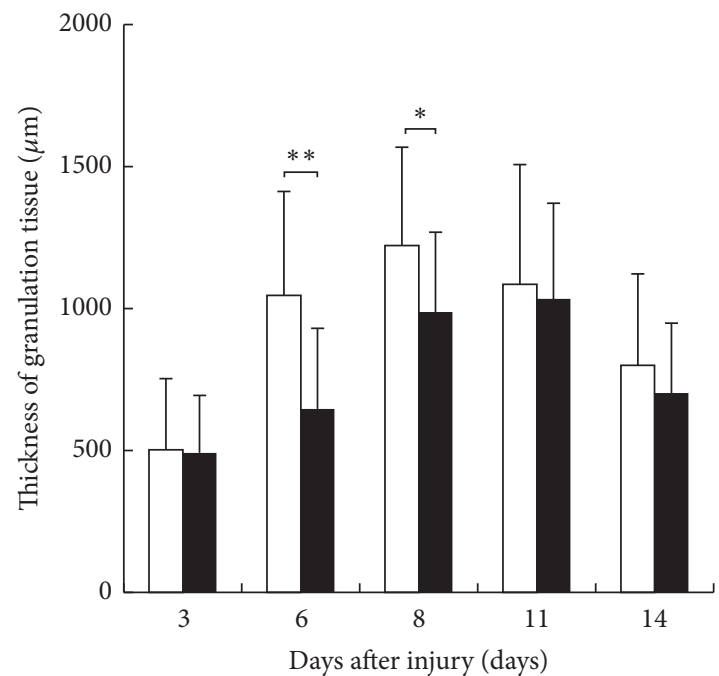

$\square$ WT

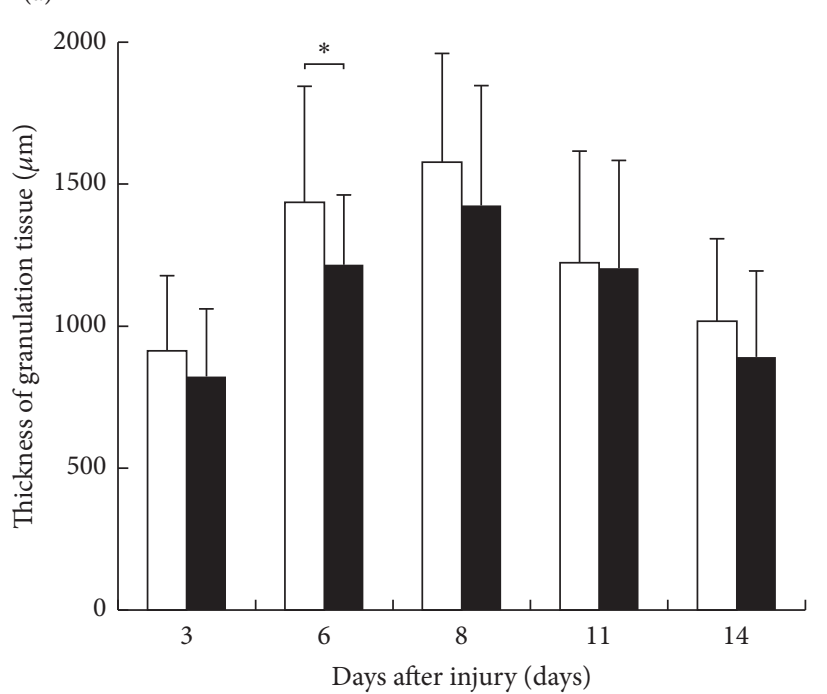

$\square \mathrm{WT}$

(b)

(c)

Figure 2: (a) Histology of healing wound tissue by hematoxylin and eosin stain at the indicated time intervals in dorsal skin of inducible nitric oxide synthase (iNOS-) knockout (KO) mice and WT mice. (b) The thickness of the granulation tissue at the center zone was thinner in KO mice than in WT mice at days 6 and 8 with a statistically significant difference. (c) At the margin zone, the thickness of the granulation tissue was significantly thinner in KO mice than in WT mice at day 6. Open bars: WT, filled bars: KO (days 3, 11, and 14: $n=6$; days 6, 8: $n=7$ animals in each group). Mean \pm standard deviation. ${ }^{*} p<0.05 ;{ }^{* *} p<0.01$; bar, $1 \mathrm{~mm}$. 


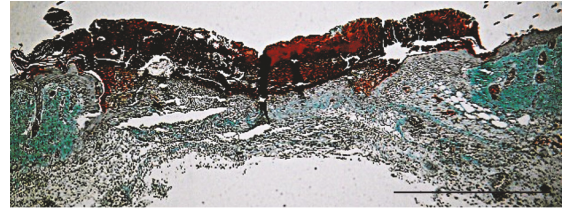

(a1)

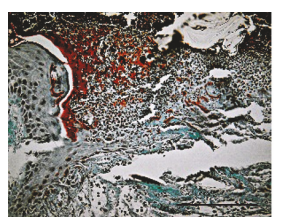

(a2)

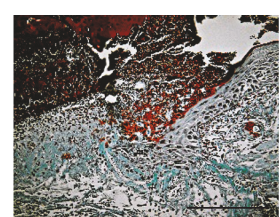

(a3)

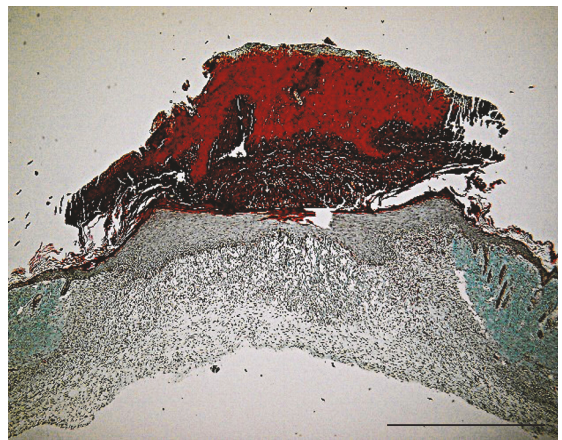

Day 6 WT 100\%
Day 3 WT 37\%

(a) (b)

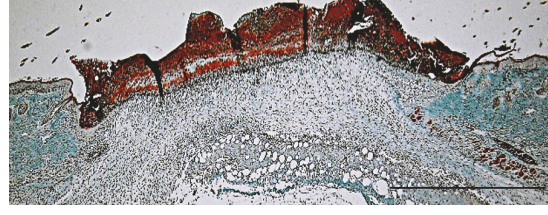

(c1)

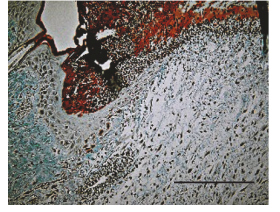

(c2)

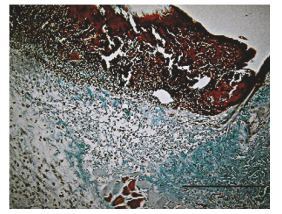

(c3)
Day 3 KO 24\%

(c)

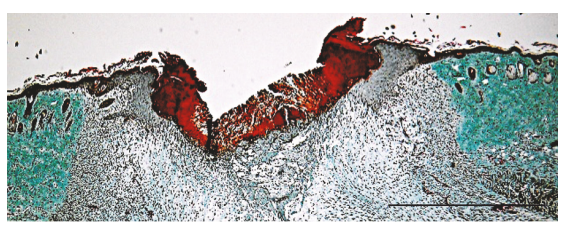

(d1) (d2)

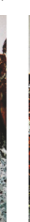

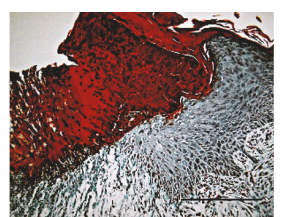

(d3)
Day 6 KO 50\%

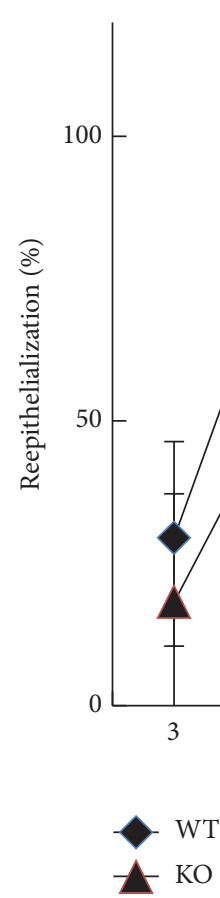

(d)

(e)

FIGURE 3: (a-d) Histological observation of reepithelialization of skin wound in wild type (WT) ((a1)-(a3), b) and inducible nitric oxide synthase (iNOS-) knockout (KO) ((c1)-(c3), (d1)-(d3)) mice at day 3 ((a1)-(a3), (c1)-(c3)) and day 6 (b, (d1)-(d3)) after injury. MassonGoldner trichrome stain was viewed at low and high magnification to measure the original wound distance and reepithelialization area, respectively. (e) The ratio of reepithelialization was evaluated. Reepithelialization was significantly delayed in KO mice at days 6 and 8 with statistical difference compared with WT mice. $\bullet$ : WT, $\mathbf{\Delta}$ : KO (days 3, 11, and 14: $n=6$; days 6, 8: $n=7$ animals in each group). Mean \pm standard deviation. ${ }^{*} p<0.05$; ${ }^{* *} p<0.01$; bar, $1 \mathrm{~mm}$ (a1, b, cl, and d1), $200 \mu \mathrm{m}$ ((a2)-(a3), (c2)-(c3), and (d2)-(d3)).

KO mouse tissues as compared with WT tissues at days 3 and 8 after injury. A previous report indicated that iNOS-null fibroblasts proliferated more slowly, synthesized less collagen, and contracted fibroblast-populated collagen lattices more slowly than WT fibroblasts [4]. Reduction of tissue TGF $\beta 1$ level could explain the reduction of myofibroblast appearance and collagen expression. However, in the uninjured tissue expression level of TGF $\beta 1, \alpha \mathrm{SMA}, \mathrm{F} 4 / 80$, and collagen I was higher in a KO mouse as compared with a WT tissue. Detailed mechanism that could explain the phenomena was to be uncovered.

Epithelial cell migration is positively modulated by $\mathrm{TGFb} /$ p38 signal [37]. Reduced level of TGFbl in tissue could explain the attenuation of epithelial healing in the absence of iNOS. Although cutaneous injury is well-repaired in normal subjects, impaired healing in diabetic patients or pressure ulcer is to be overcome. Reduction of NO level in tissue is associated with such attenuation of tissue repair conditions. 
WT

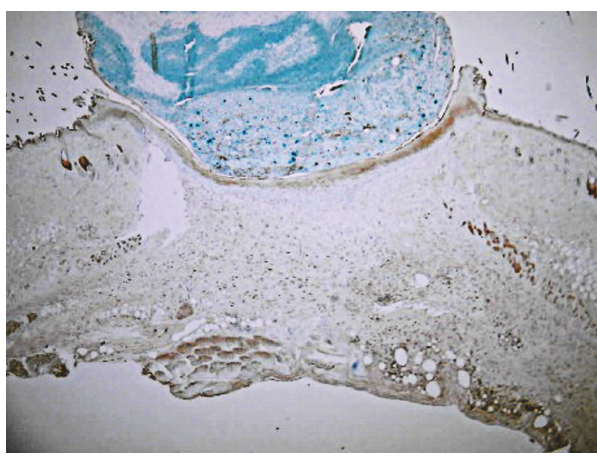

(a)

KO

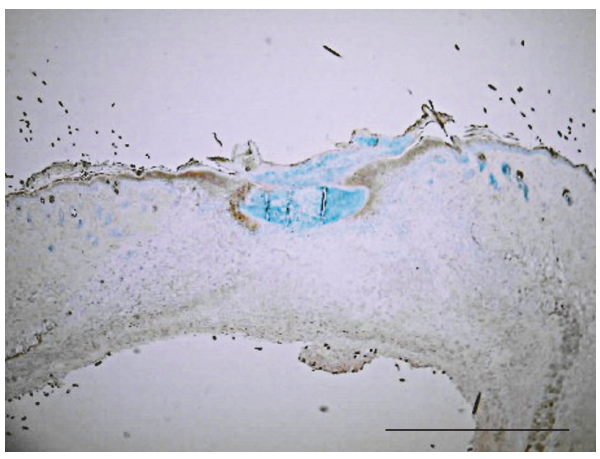

(c)
WT

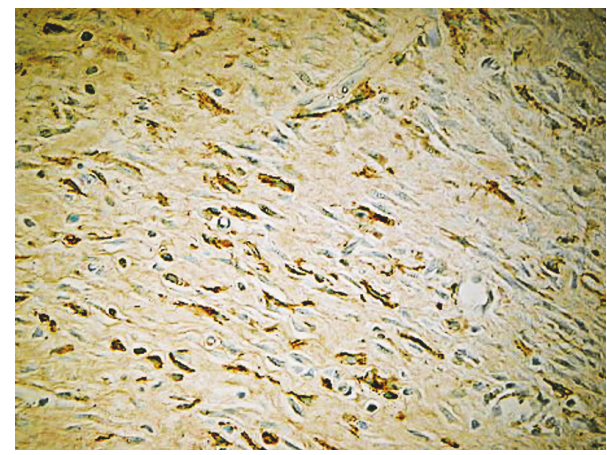

(b)

KO

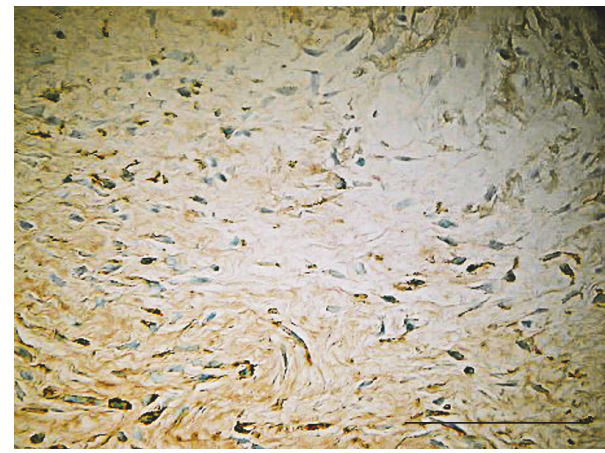

(d)

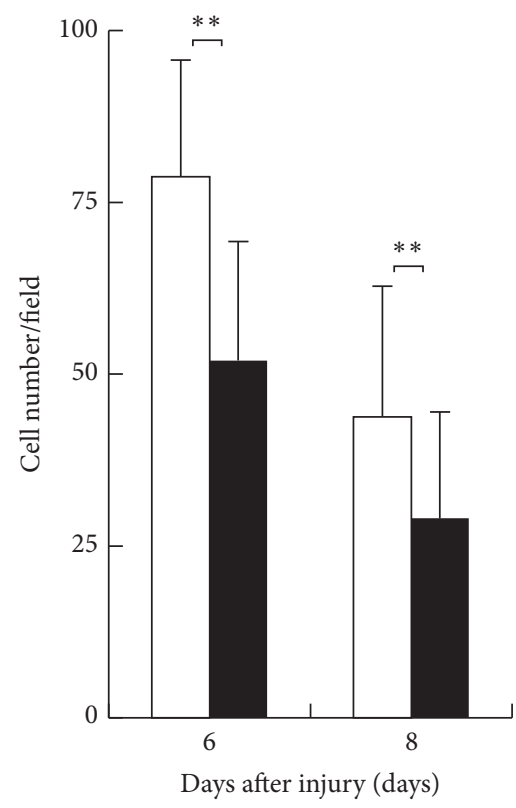

$\square \mathrm{WT}$

KO

(e)

FIGURE 4: (a-d) Immunohistochemical observation of F4/80-labeled macrophages. Skin wound samples of wild type (WT) (a, b) and inducible nitric oxide synthase (iNOS-) knockout $(\mathrm{KO})(\mathrm{c}, \mathrm{d}$ ) mice indicate findings at day 6 after injury. (e) The numbers of F4/80-positive macrophages within a wound bed were enumerated on these five visual fields and analyzed macrophage recruitment. The infiltration of F4/80 labeled macrophages in $\mathrm{KO}$ mice was reduced with a statistical significance compared with WT mice at days 6 and 8 after injury. Open bars: WT, filled bars: iKO (days 6, 8: $n=7$ animals in each group). Mean \pm standard deviation. ${ }^{* *} p<0.01$; bar $10 \mu \mathrm{m}$. 
WT

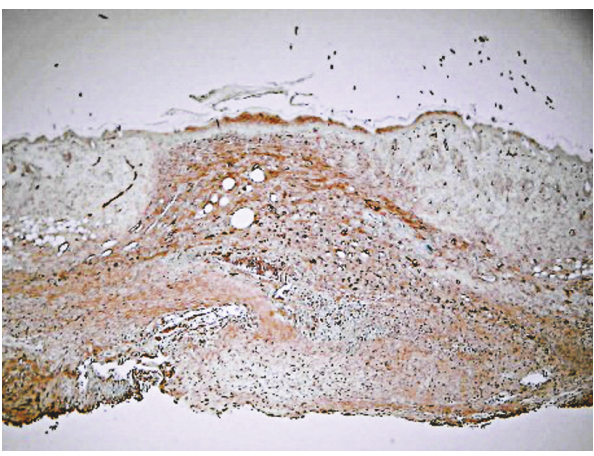

(a)

KO

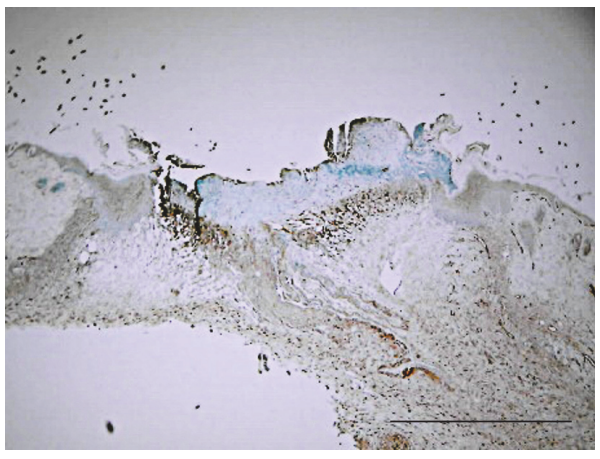

(c)
WT

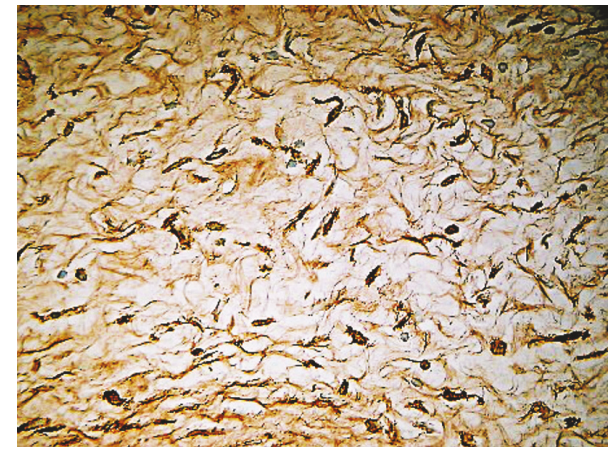

(b)

$\mathrm{KO}$

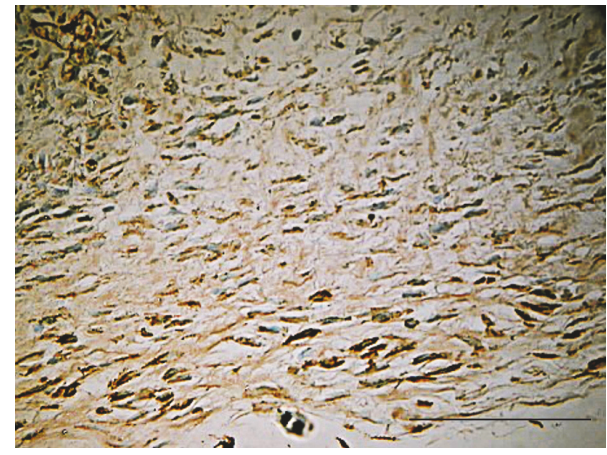

(d)

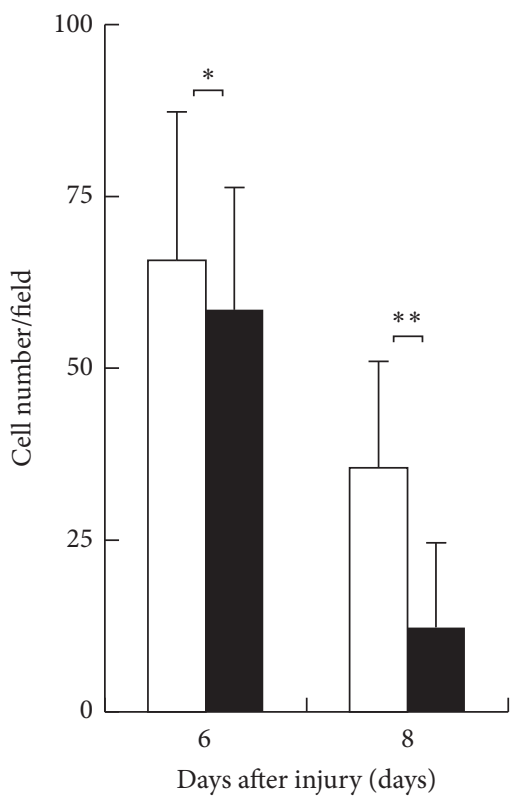

$\square$ WT

$\mathrm{KO}$

(e)

FIGURE 5: (a-d) Immunohistochemical observation of myofibroblasts as detected by $\alpha$-smooth muscle actin ( $\alpha$ SMA). Skin wound samples of wild type (WT) (a,b) and inducible nitric oxide synthase (iNOS-) knockout (KO) (c, d) mice indicate findings at day 6 after injury. (e) The numbers of myofibroblasts within a wound bed were enumerated on these five visual fields and analyzed. The appearance of myofibroblasts as detected by $\alpha$ SMA in KO mice was reduced with a statistical significance compared with WT mice at days 6 and 8 after injury. Open bars: WT, filled bars: KO (days 6, 8: $n=7$ animals in each group). Mean \pm standard deviation. ${ }^{*} p<0.05 ;{ }^{* *} p<0.01$; bar $10 \mu \mathrm{m}$. 


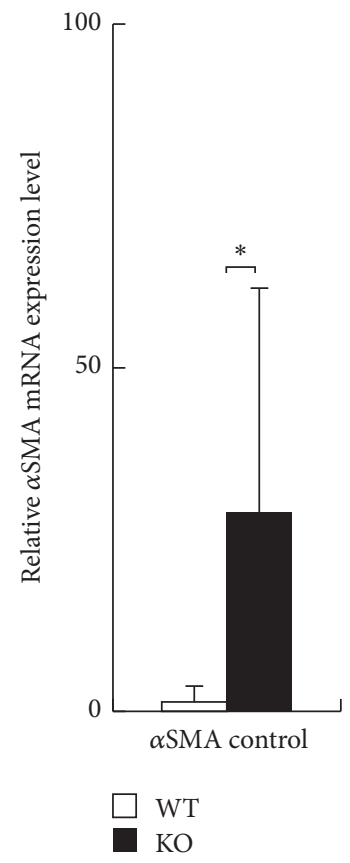

(a)

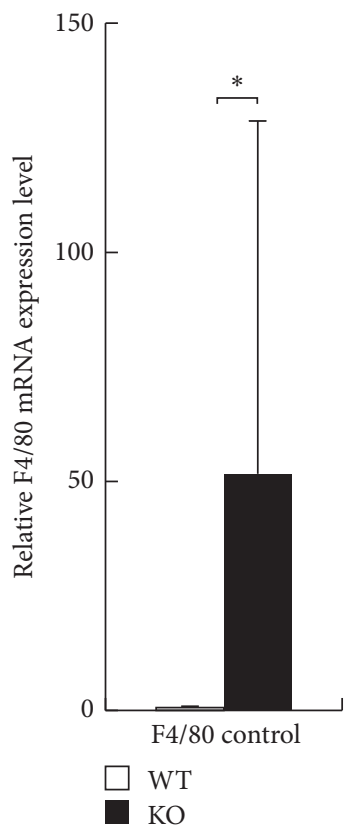

(b)

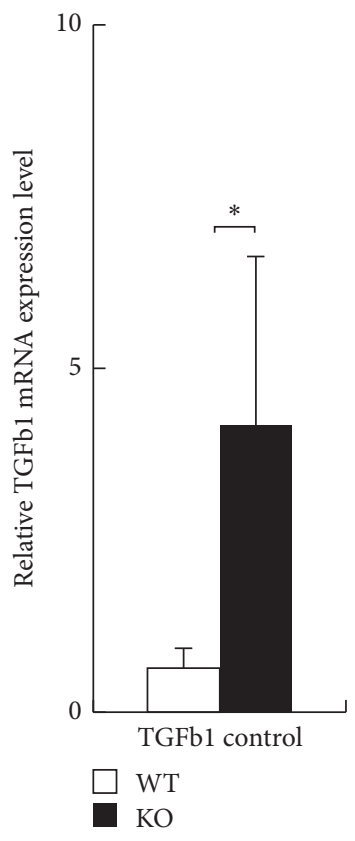

(c)

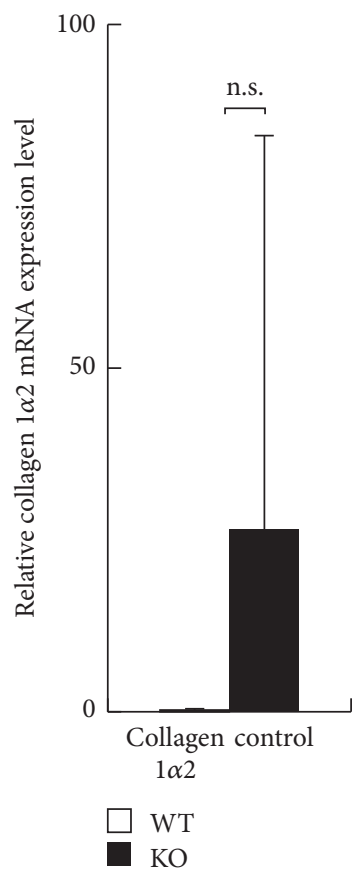

(d)

FIGURE 6: Expression of mRNA of $\alpha$-smooth muscle actin ( $\alpha$ SMA), F4/80, transforming growth factor $\beta 1$ (TGF $\beta 1$ ), and collagen $1 \alpha 2$ in normal skin of wild type (WT) and inducible nitric oxide synthase (iNOS-) knockout (KO) mice. (a-c) Expression of $\alpha$ SMA, F4/80 and TGF $\beta 1$ mRNA was significantly more marked in KO normal skin compared with WT tissues. (d) Expression level of collagen $1 \alpha 2$ mRNA was more prominent in KO normal skin, but there was no significant difference between WT and KO. Open bars: WT, filled bars: KO. Mean \pm standard deviation. ${ }^{*} p<0.05$; n.s., not significant.

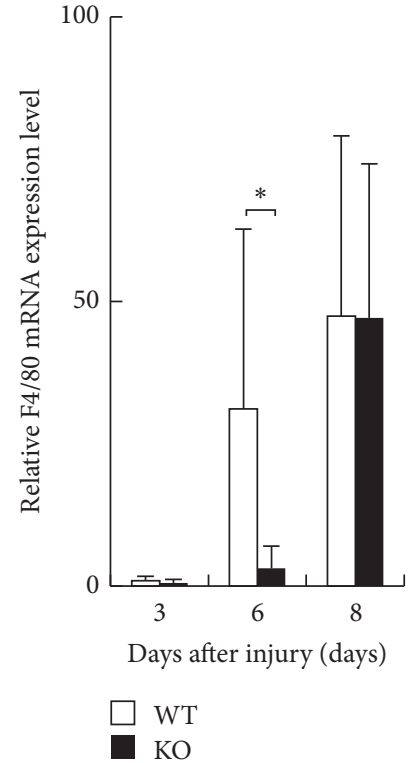

(a)

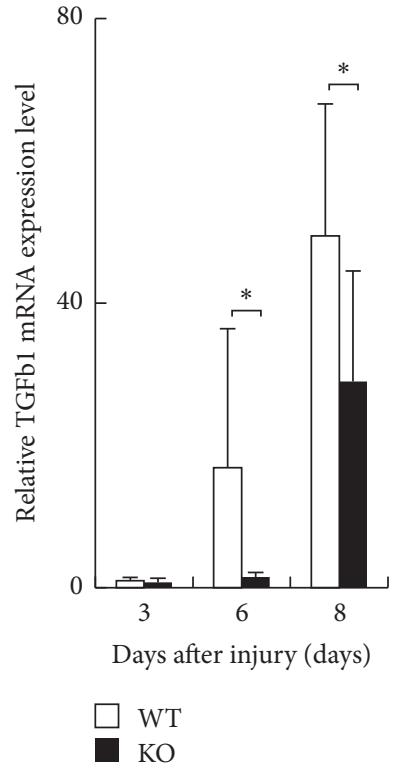

(b)

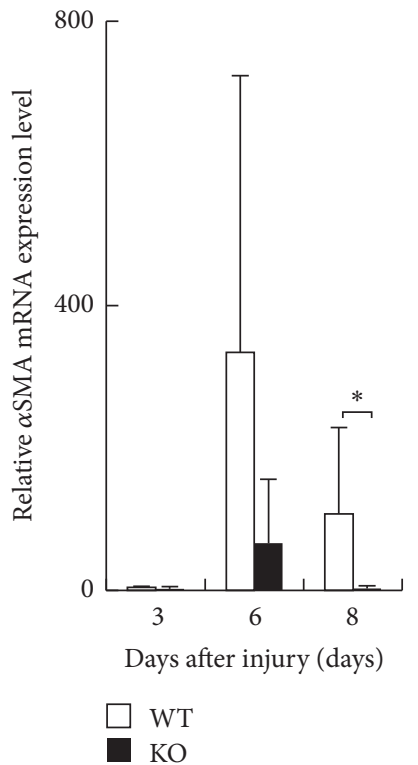

(c)

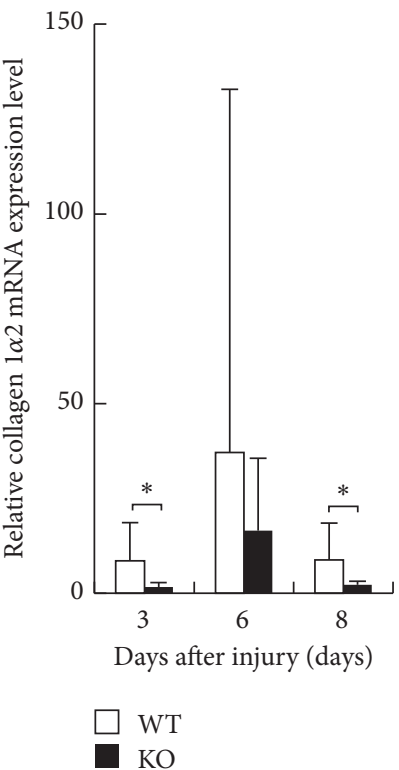

(d)

FIGURE 7: Expression of mRNA of $\alpha$-smooth muscle actin ( $\alpha$ SMA), F4/80, transforming growth factor $\beta 1$ (TGF $\beta 1$ ), and collagen $1 \alpha 2$ in healing tissues of wild type (WT) and inducible nitric oxide synthase (iNOS-) knockout (KO) mice at days 3, 6, and 8. (a) F4/80 mRNA expression was significantly more suppressed in KO tissues at day 6 as compared with WT tissues. (b) Expression of TGF $\beta 1$ mRNA was significantly attenuated in $\mathrm{KO}$ tissues as compared with WT tissues at days 6 and 8. (c) Expression of $\alpha$ SMA mRNA was significantly less marked in KO tissues at day 8 as compared with WT tissues. (d) Collagen $1 \alpha 2$ mRNA expression was reduced in KO tissues as compared with WT tissues at days 3 and 8 with statistically significant difference. Open bars: WT, filled bars: KO. Mean \pm standard deviation. ${ }^{*} p<0.05$; n.s., not significant. 
Strategy to supply NO is considered to be one of the efficient ones in the treatment of impaired cutaneous wound healing.

\section{Conclusion}

The present study indicates that iNOS is required in the process of cutaneous wound healing. Lacking iNOS retards macrophage invasion and its expression of fibrogenic components that might further impair fibrogenic behaviors of fibroblasts.

\section{Disclosure}

Institutional web page is http://www.wakayama-med.ac.jp/med/ eccm/intro/staff/core/index.html.

\section{Conflicts of Interest}

The authors declare that they have no conflicts of interest.

\section{Acknowledgments}

This study was supported by grants from the Ministry of Education, Science, Sports and Culture of Japan (C16K10834 to Hiroshi Yamada, C25462829 to Maki Kida, C15K10878 to Yuka Okada, C25462729 to Shizuya Saika, and C23592173 to Munehito Yoshida) and NEI Eye Research Grant EY021510 (Jester).

\section{References}

[1] A. J. Singer and R. A. F. Clark, "Cutaneous wound healing," New England Journal of Medicine, vol. 341, no. 10, pp. 738-746, 1999.

[2] P. Martin, "Wound healing-aiming for perfect skin regeneration," Science, vol. 276, no. 5309, pp. 75-81, 1997.

[3] M. K. Lichtman, M. Otero-Vinas, and V. Falanga, "Transforming growth factor beta (TGF- $\beta$ ) isoforms in wound healing and fibrosis," Wound Repair and Regeneration, vol. 24, no. 2, pp. 215222, 2016

[4] H. P. Shi, D. T. Efron, D. Most, U. Tantry, and A. Barbul, "The role of iNOS in wound healing," Surgery, vol. 130, no. 2, pp. 225229, 2001.

[5] T. R. Lizarbe, C. García-Rama, C. Tarín et al., "Nitric oxide elicits functional MMP-13 protein-tyrosine nitration during wound repair," The FASEB Journal, vol. 22, no. 9, pp. 3207-3215, 2008.

[6] H. P. Shi, D. T. Efron, D. Most, U. S. Tantry, and A. Barbul, "Supplemental dietary arginine enhances wound healing in normal but not inducible nitric oxide synthase knockout mice," Surgery, vol. 128, no. 2, pp. 374-378, 2000.

[7] D. Most, D. T. Efron, Han Ping Shi, U. S. Tantry, and A. Barbul, "Differential cytokine expression in skin graft healing in inducible nitric oxide synthase knockout mice," Plastic and Reconstructive Surgery, vol. 108, no. 5, pp. 1251-1259, 2001.

[8] D. Most, D. T. Efron, H. P. Shi, U. S. Tantry, and A. Barbul, "Characterization of incisional wound healing in inducible nitric oxide synthase knockout mice," Surgery, vol. 132, no. 5, pp. 866-876, 2002.
[9] A. K. Nussler and T. R. Billiar, "Inflammation, immunoregulation, and inducible nitric oxide synthase," Journal of Leukocyte Biology, vol. 54, no. 2, pp. 171-178, 1993.

[10] R. H. Lee, D. Efron, U. Tantry, and A. Barbul, "Nitric oxide in the healing wound: a time-course study," Journal of Surgical Research, vol. 101, no. 1, pp. 104-108, 2001.

[11] J. E. Jang, M. S. Ko, J. Yun et al., "Nitric oxide produced by macrophages inhibits adipocyte differentiation and promotes profibrogenic responses in preadipocytes to induce adipose tissue fibrosis," Diabetes, vol. 65, no. 9, pp. 2516-2528, 2016.

[12] J. Zhou, N. Dehne, and B. Brüne, "Nitric oxide causes macrophage migration via the HIF-1-stimulated small GTPases Cdc42 and Racl," Free Radical Biology and Medicine, vol. 47, no. 6, pp. 741-749, 2009.

[13] M.-C. Maa, Y. C. Miao, Y.-J. Chen et al., "Requirement of inducible nitric-oxide synthase in lipopolysaccharide- mediated Src induction and macrophage migration," Journal of Biological Chemistry, vol. 283, no. 46, pp. 31408-31416, 2008.

[14] S. Saika, A. Shiraishi, S. Saika et al., "Role of lumican in the corneal epithelium during wound healing," Journal of Biological Chemistry, vol. 275, no. 4, pp. 2607-2612, 2000.

[15] S. Saika, K. Shirai, O. Yamanaka et al., "Loss of osteopontin perturbs the epithelial-mesenchymal transition in an injured mouse lens epithelium," Laboratory Investigation, vol. 87, no. 2, pp. 130-138, 2007.

[16] R. Mori, T. Kondo, T. Ohshima, Y. Ishida, and N. Mukaida, "Accelerated wound healing in tumor necrosis factor receptor p55-deficient mice with reduced leukocyte infiltration," The FASEB Journal, vol. 16, no. 9, pp. 963-974, 2002.

[17] M. Shinozaki, Y. Okada, A. Kitano, K. Ikeda, S. Saika, and M. Shinozaki, "Impaired cutaneous wound healing with excess granulation tissue formation in TNF $\alpha$-null mice," Archives of Dermatological Research, vol. 301, no. 7, pp. 531-537, 2009.

[18] J. V. Dovi, L.-K. He, and L. A. DiPietro, "Accelerated wound closure in neutrophil-depleted mice," Journal of Leukocyte Biology, vol. 73, no. 4, pp. 448-455, 2003.

[19] Q. E. H. Low, I. A. Drugea, L. A. Duffner et al., "Wound healing in MIP-1 $\alpha-/$ - and MCP-1-/- mice," American Journal of Pathology, vol. 159, no. 2, pp. 457-463, 2001.

[20] R. Mori, T. Kondo, T. Nishie, T. Ohshima, and M. Asano, "Impairment of skin wound healing in $\beta$-1,4-galactosyltransferase-deficient mice with reduced leukocyte recruitment," American Journal of Pathology, vol. 164, no. 4, pp. 1303-1314, 2004.

[21] M. E. Swift, H. K. Kleinman, and L. A. DiPietro, "Impaired wound repair and delayed angiogenesis in aged mice," Laboratory Investigation, vol. 79, no. 12, pp. 1479-1487, 1999.

[22] S. Saika, K. Ikeda, O. Yamanaka et al., "Loss of tumor necrosis factor $\alpha$ potentiates transforming growth factor $\beta$-mediated pathogenic tissue response during wound healing," American Journal of Pathology, vol. 168, no. 6, pp. 1848-1860, 2006.

[23] S. Saika, T. Miyamoto, O. Yamanaka et al., "Therapeutic effect of topical administration of SN50, an inhibitor of nuclear factor$\kappa \mathrm{B}$, in treatment of corneal alkali burns in mice," American Journal of Pathology, vol. 166, no. 5, pp. 1393-1403, 2005.

[24] Z.-Q. Lin, T. Kondo, Y. Ishida, T. Takayasu, and N. Mukaida, "Essential involvement of IL-6 in the skin wound-healing process as evidenced by delayed wound healing in IL-6-deficient mice," Journal of Leukocyte Biology, vol. 73, no. 6, pp. 713-721, 2003. 
[25] T. Nagaoka, Y. Kaburagi, Y. Hamaguchi et al., "Delayed wound healing in the absence of intercellular adhesion molecule-1 or L-selectin expression," American Journal of Pathology, vol. 157, no. 1, pp. 237-247, 2000.

[26] S. Saika, K. Ikeda, O. Yamanaka et al., "Expression of Smad7 in mouse eyes accelerates healing of corneal tissue after exposure to alkali," American Journal of Pathology, vol. 166, no. 5, pp. 1405-1418, 2005.

[27] S. Saika, K. Ikeda, O. Yamanaka et al., "Therapeutic effects of adenoviral gene transfer of bone morphogenic protein-7 on a corneal alkali injury model in mice," Laboratory Investigation, vol. 85, no. 4, pp. 474-486, 2005.

[28] S. Saika, K. Ikeda, O. Yamanaka et al., "Adenoviral gene transfer of BMP-7, Id2, or Id3 suppresses injury-induced epithelial-tomesenchymal transition of lens epithelium in mice," American Journal of Physiology-Cell Physiology, vol. 290, no. 1, pp. 282289, 2006.

[29] M. R. Schäffer, U. Tantry, P. A. Efron, G. M. Ahrendt, F. J. Thornton, and A. Barbul, "Diabetes-impaired healing and reduced wound nitric oxide synthesis: a possible pathophysiologic correlation," Surgery, vol. 121, no. 5, pp. 513-519, 1997.

[30] M. R. Schaffer, U. Tantry, G. M. Ahrendt, H. L. Wasserkrug, and A. Barbul, "Acute protein-calorie malnutrition impairs wound healing: a possible role of decreased wound nitric oxide synthesis," Journal of the American College of Surgeons, vol. 184, no. 1, pp. 37-43, 1997.

[31] K. Yamasaki, H. D. J. Edington, C. McClosky et al., "Reversal of impaired wound repair in iNOS-deficient mice by topical adenoviral-mediated iNOS gene transfer," Journal of Clinical Investigation, vol. 101, no. 5, pp. 967-971, 1998.

[32] B. J. Cohen, D. Danon, and G. S. Roth, "Wound repair in mice as influenced by age and antimacrophage serum," Journals of Gerontology, vol. 42, no. 3, pp. 295-301, 1987.

[33] S. Saika, “TGF $\beta$ pathobiology in the eye," Laboratory Investigation, vol. 86, no. 2, pp. 106-115, 2006.

[34] H. Takaki, Y. Minoda, K. Koga, G. Takaesu, A. Yoshimura, and T. Kobayashi, "TGF- $\beta 1$ suppresses IFN- $\gamma$-induced NO production in macrophages by suppressing STAT1 activation and accelerating iNOS protein degradation," Genes to Cells, vol. 11, no. 8, pp. 871-882, 2006.

[35] R. A. F. Clark, L. D. Nielsen, M. P. Welch, and J. M. McPherson, "Collagen matrices attenuate the collagen-synthetic response of cultured fibroblasts to TGF- $\beta$," Journal of Cell Science, vol. 108, no. 3, pp. 1251-1261, 1995.

[36] R. Montesano and L. Orci, "Transforming growth factor beta stimulates collagen-matrix contraction by fibroblasts: implications for wound healing," Proceedings of the National Academy of Sciences of the United States of America, vol. 85, no. 13, pp. 48944897, 1988.

[37] G. Pelaia, G. Cuda, A. Vatrella et al., "Mitogen-activated protein kinases and asthma," Journal of Cellular Physiology, vol. 202, no. 3, pp. 642-653, 2005. 


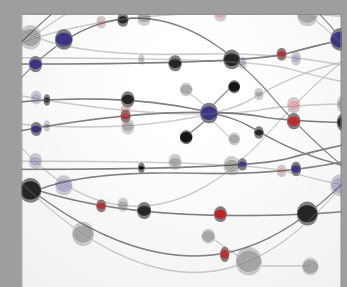

The Scientific World Journal
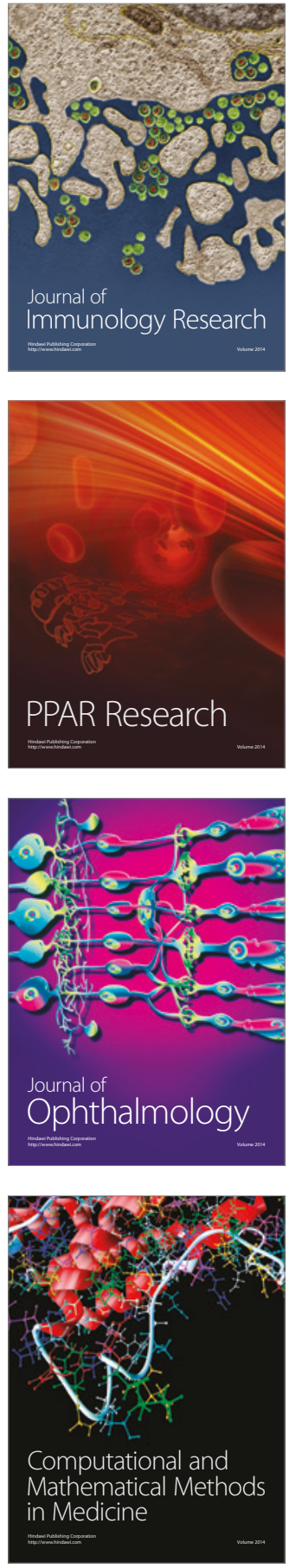

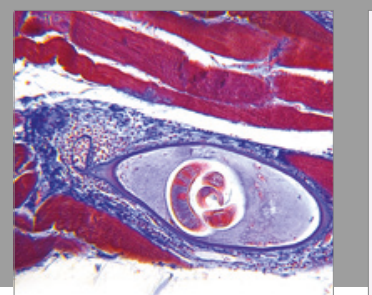

Gastroenterology Research and Practice
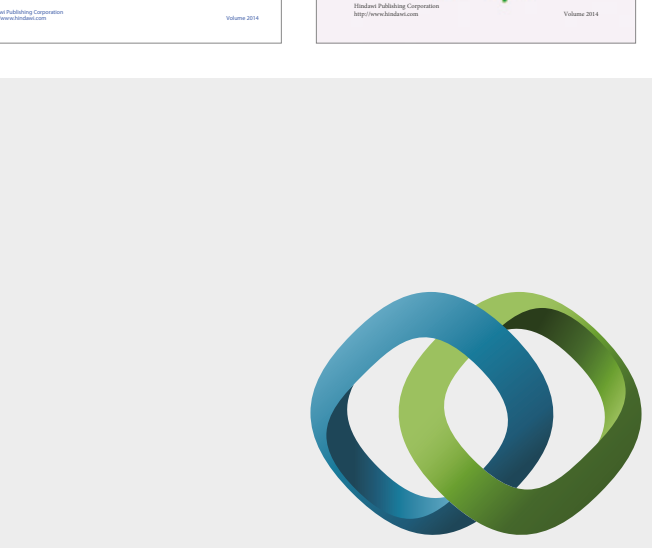

\section{Hindawi}

Submit your manuscripts at

https://www.hindawi.com
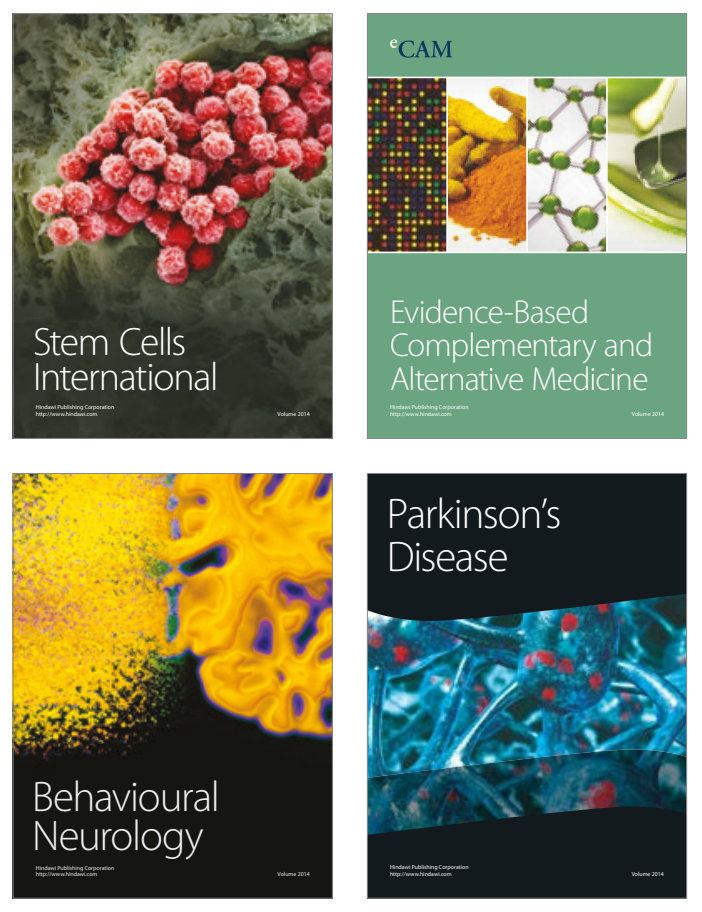
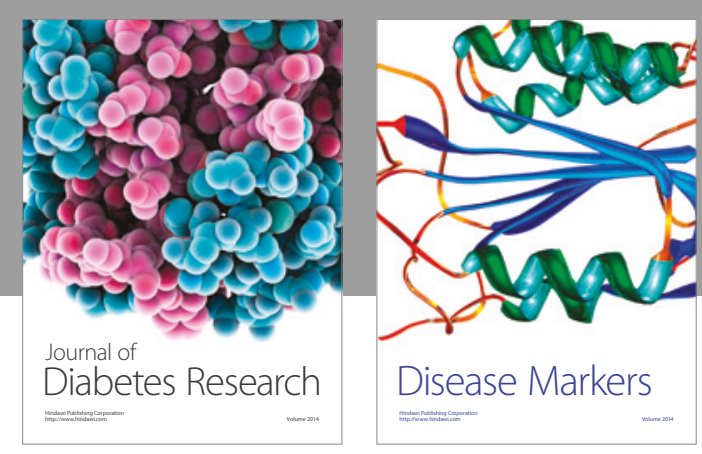

Disease Markers
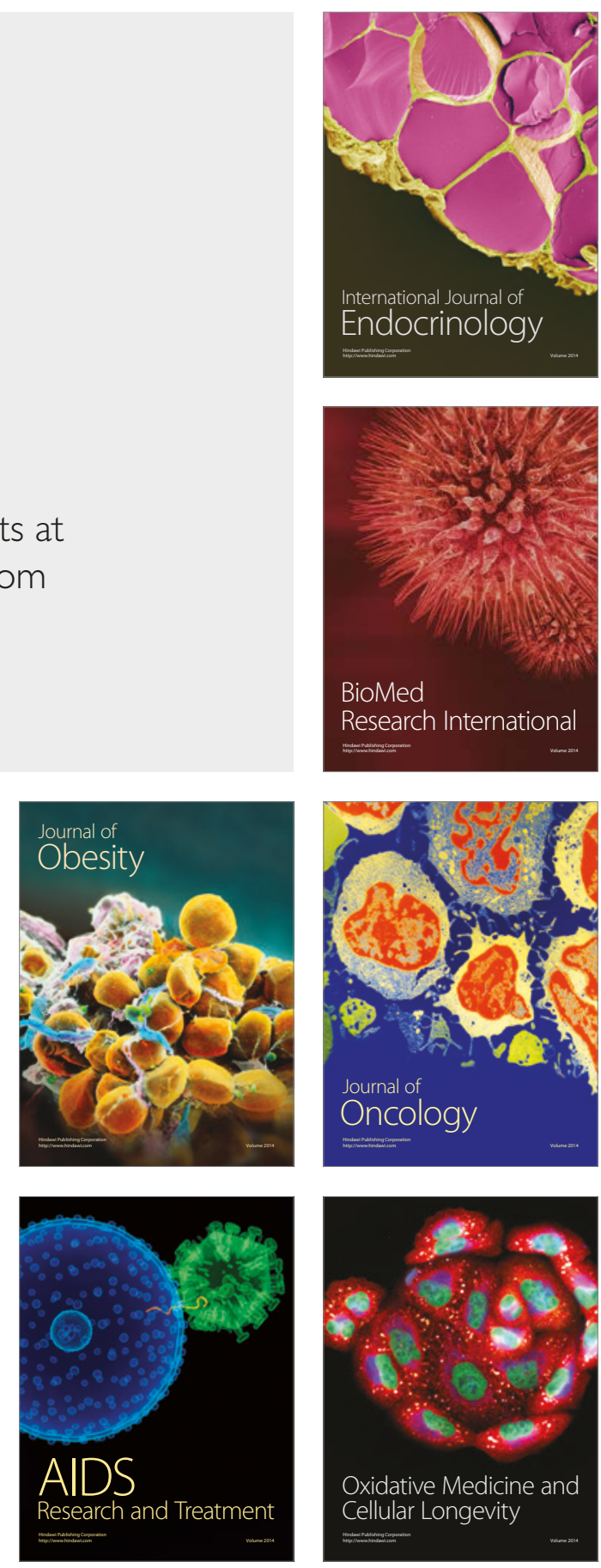